\title{
AVALIAÇÃO DE MANIFESTAÇÕES PATOLÓGICAS EM ESTABELECIMENTO PRISIONAL NO RIO GRANDE DO SUL E ALTERNATIVAS DE RECUPERAÇÃO
}

\author{
MATIAS, FERNANDA \\ Estudante de Graduação \\ UFRGS \\ RS; BRASIL \\ fematiias@gmail.com
}

\author{
MENEGON, JULIA \\ Eng $^{\mathrm{a}}$. Civil \\ UFRGS \\ RS; BRASIL \\ menegonjulia@gmail.com
}

\author{
KAUSS, CAROLINE DA SILVA \\ Enga . Civil \\ SUSEPE-RS \\ RS; BRASIL \\ carol_kauss@hotmail.com
}

\author{
COSTA, CARLOS EDUARDO IPONEMA \\ Arquiteto \\ UNIFTEC-POA \\ RS; BRASIL \\ iponema@hotmail.com
}

\section{RESUMO}

Manifestações patológicas ocorrem devido às ações do tempo, agentes agressivos, umidade ou falhas na execução. Este artigo trata de patologias estruturais observadas em um Estabelecimento Penal localizado em Porto Alegre, Rio grande do Sul. Dada a possibilidade de comprometimento da estrutura, foi realizado um estudo de caso partindo de inspeção visual, seguido por ensaios de avaliação da carbonatação do concreto, da perda de seção do aço e do grau de deterioração da estrutura. O resultado foi uma estrutura com elevado grau de carbonatação, avançado estado de corrosão de armadura, redução considerável de seção de aço e desplacamento de concreto. As manifestações patológicas foram provocadas pela infiltração de água, dado o uso da edificação como lavanderia da casa prisional. Os resultados da vistoria permitiram levantar sugestões de intervenções para a recuperação da vida útil da estrutura. As soluções foram pautadas considerando-se a tipologia de projeto adotada e o uso da edificação.

Palavras-chave: patologia, estabelecimento prisional, recuperação estrutural, corrosão, carbonatação.

\section{ABSTRACT}

Building pathologies are damages to structures due to weathering, aggressive agents, presence of water or failure in construction. This paper discusses the structural pathologies observed in a penal institution located in the city of Porto Alegre, Rio Grande do Sul. Given the possibility of compromising the structure, a case study was carried, initially based on visual inspection, followed by tests to evaluate the carbonation of the concrete, the reinforced bar section loss and the degree of deterioration of the structure. The data gathered indicate a structure with a high degree of carbonation, advanced stage of reinforcement corrosion, considerable reduction of bars cross-sectional area and spalling of concrete cover. The damages were possibly caused by water infiltration, due to the use of the building as a laundry. The results of the visual inspection made it possible to raise suggestions for interventions aiming at the recovery of the structure's life cycle. The repair to be taken for the rehabilitation was based on the design typology and the use of the building. Keywords: Building pathology, prison, structural rehabilitation, corrosion, carbonation.

\section{INTRODUÇÃO}

Os estabelecimentos prisionais, também conhecidos antigamente como casas de correção ou casas de detenção, existem há séculos no brasil, desde a colonização, e surgiram com o intuito de punir as pessoas que possuíam mau comportamento ou que cometeram algum crime perante a sociedade. Devido a tal conduta rebelde, estes indivíduos depredavam os locais onde eram privados de sua liberdade, deteriorando a estrutura destes ambientes, os quais apresentavam diversas manifestações patológicas resultantes das ações humanas somadas às intempéries (MAIA et al, 2013).

Toda e qualquer estrutura possui uma vida útil de projeto, entretanto, ao longo dos anos surgem intervenções que não são previstas, como sinistros ambientais, mau uso e até mesmo falha na sua construção e/ou manutenção, que acabam reduzindo drasticamente o seu desempenho e durabilidade. Nesse aspecto, as edificações apresentam alguns indícios de 
que o seu desempenho está sendo afetado. Tais sinais são denominados de anomalias e falhas, os quais são classificados de acordo com a sua origem e o seu grau de risco (IBAPE, 2012). Em alguns casos os sinais podem ser imperceptíveis aos olhos de grande parte dos leigos, ou até mesmo demorarem a se manifestar (TUTIKIAN; PACHECO, 2011).

A falta de inspeção e manutenção predial prejudica a detecção precoce das patologias em desenvolvimento, as quais poderiam ser solucionadas antes de seu avanço, podendo levar ao comprometimento dos elementos afetados.

Neste sentido, o presente estudo foi realizado devido à necessidade de avaliar o grau de deterioração do sistema estrutural de um prédio destinado ao tratamento de pacientes em medida de segurança, cujas manifestações patológicas atingiram dimensões preocupantes. Este trabalho, portanto, buscou realizar um diagnóstico das patologias existentes, avaliando os prováveis fatores desencadeadores das mesmas e indicando as intervenções possíveis e necessárias para retomar o desempenho e a segurança da edificação, permitindo restabelecer o uso do prédio em questão, dada a alta demanda por vagas no setor prisional.

\subsection{Corrosão de Armadura}

De acordo com a NBR 6118 (ABNT, 2014), são cinco os mecanismos causadores de envelhecimento e deterioração das estruturas de concreto armado, sendo lixiviação, expansão por sulfato e reação álcali-agregado os mecanismos preponderantes para o concreto, e despassivação por carbonatação e por ação de cloretos para a armadura.

A manifestação patológica de maior ocorrência em estruturas de concreto, segundo Helene (1992), tem sido a corrosão de armaduras. A armadura envolta pelo concreto está protegida da ação de agentes químicos por meio de barreiras física e química que este proporciona. A barreira física trata-se da separação entre a armadura e o meio externo, enquanto o elevado $\mathrm{pH}$ do concreto promove a proteção química do aço, pela formação de película passivadora. Com a penetração de agentes agressivos a camada passivadora perde sua estabilidade, devido à redução da alcalinidade, conduzindo ao processo de corrosão da armadura (FIGUEIREDO; MEIRA, 2011).

O processo de corrosão pode se dar de forma localizada, em que uma superfície limitada do aço sofre desgaste, ou generalizada, ocorrendo desgaste em uma área extensa do material. Segundo Figueiredo e Meira (2011), o primeiro caso está associado à ação de íons cloreto, enquanto o segundo se relaciona ao processo de carbonatação do concreto. Com o avanço da corrosão, manchas alaranjadas começam a aparecer na superfície do elemento, além de fissurações no concreto de cobrimento, podendo ocasionar o destacamento desta porção (Figura 1).

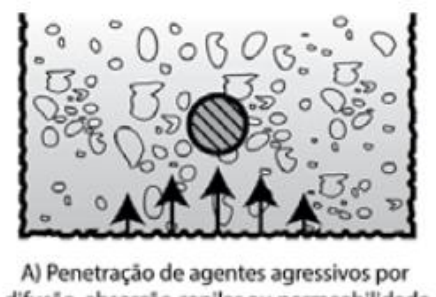
difusăo, absorçắo capilar ou permeabilidade

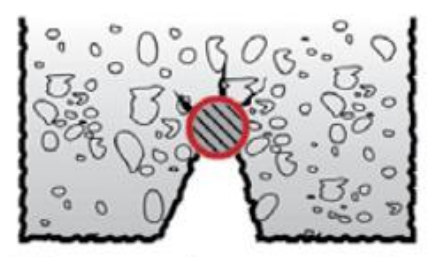

C) Destacamento do concreto e corrosão acentuada

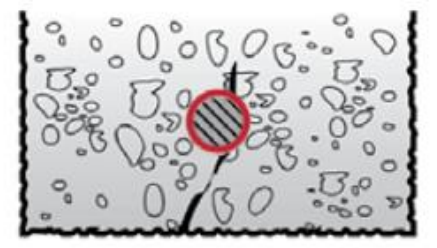

B) Fissuração devida as forças de expansão dos produtos de corrosão

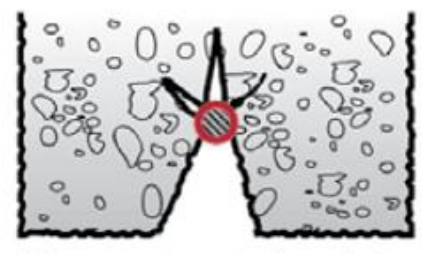

D) Destacamento acentuado e redução significativa da seç̧ấo da armadura

Figura 1: Evolução da deterioração de estruturas de concreto por corrosão de armaduras (Helene,1986)

Figueiredo e Meira (2011) citam que nesse momento, a vida útil de serviço ou utilização da estrutura chega ao fim. Caso nenhuma intervenção seja realizada nesta fase, o processo corrosivo segue em desenvolvimento, causando perda de seção da armadura e de aderência da mesma ao concreto. Este grau de degradação indica o ponto de mínimo desempenho do elemento, podendo chegar a ruptura ou colapso, parcial ou total.

A NBR 15575 (ABNT, 2013) afirma que é possível prolongar a vida útil através de ações de manutenção na estrutura, que recuperem, ao menos parcialmente, seu desempenho, conforme gráfico da figura 2. Quanto mais cedo essas intervenções ocorrerem, mais eficientes e menos onerosas serão (TUTIKIAN; PACHECO, 2011). 


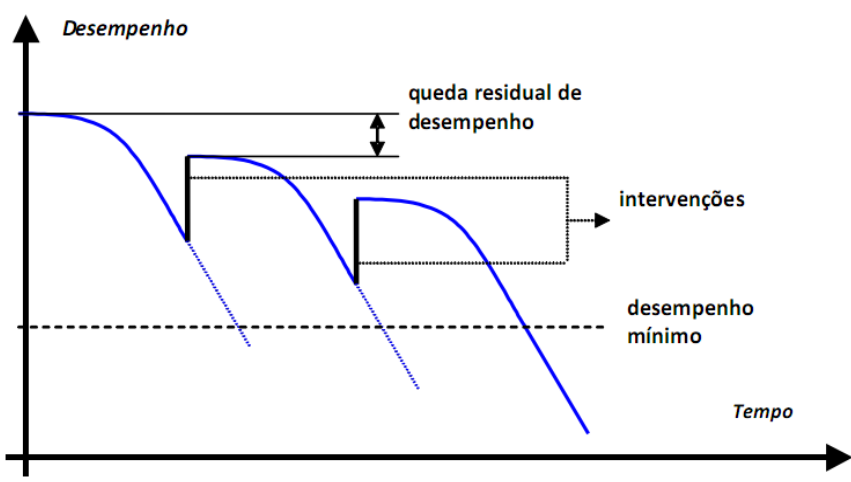

Figura 2: Desempenho x tempo (LICHTENSTEIN, 1985, apud SOUZA; MONTEIRO; BATISTA, 2017)

Para diagnosticar os problemas observados, é realizada inicialmente uma inspeção visual, através da qual as características gerais são levantadas e dados preliminares são obtidos. Em caso de se fazer necessário, ensaios complementares podem ser realizados, visando obter informações adicionais específicas acerca das anomalias, que auxiliem o diagnóstico.

\subsection{Métodos de Avaliação}

Além da inspeção visual, as características das estruturas acabadas podem ser determinadas por diversos métodos de avaliação, com diferentes graus de complexidade. Tais métodos envolvem ensaios destrutivos, semidestrutivos e não destrutivos. Como o próprio nome sugere, a diferença entre as intervenções é o nível de dano causado ao elemento para a realização dos ensaios. Métodos destrutivos envolvem a retirada de amostras da estrutura existente para análise laboratorial. Nesta categoria estão os ensaios de resistência à compressão do concreto, realizados através da extração de corpos de prova dos elementos de interesse.

Métodos não destrutivos, por sua vez, não geram nenhum dano ao elemento. Incluem-se neste grupo ensaios para avaliar a qualidade do concreto, como esclerometria, velocidade do pulso ultrassônico e ecografia e para localizar o posicionamento de armaduras, como a pacometria. Entre os dois métodos supracitados, está o método semidestrutivo, que causa pequenos danos superficiais à estrutura. Como exemplo tem-se a abertura de janelas de inspeção, por meio das quais faz-se possível a investigação de elementos estruturais sem causar grandes avarias aos mesmos.

\section{PROCEDIMENTOS}

Esta pesquisa está baseada em patologias ocorridas em um estabelecimento penal, situado no município de Porto Alegre/RS. Tal estabelecimento é dirigido ao cumprimento de medida de segurança por indivíduos que, embora tenham cometido algum crime, foram considerados pelo Poder Judiciário Criminal como Inimputáveis por externar transtorno mental.

O instituto penal em questão foi inaugurado há cerca de 95 anos, e apresenta características físicas bastante similares a albergues. Contempla diversas edificações, dentre as quais uma delas serviu como objeto da presente análise. $\mathrm{O}$ edifício em estudo é composto por dois pavimentos acima do nível do solo e um pavimento no subsolo (Figura 3). O uso deste pavilhão se destinava a abrigar pessoas privadas de liberdade, do sexo masculino, e era constituído por alojamentos e sanitários, ambos coletivos.

A presente pesquisa foi delimitada ao subsolo do pavilhão por se tratar da estrutura com maior grau de deterioração. No subsolo a estrutura é composta por pilares de alvenaria de tijolos maciços, vigas e lajes de concreto armado. As paredes de vedação, bem como as paredes internas são compostas de alvenaria ora de tijolos maciços, ora de tijolos furados, pintados interna e externamente.

A estrutura da edificação está bastante precária, sendo que alguns pontos apresentam sérios problemas de mofo, infiltrações, degradação da pintura e desplacamento do concreto. Cabe salientar que no pavimento superior à área em estudo, o espaço foi utilizado durante certo período como lavanderia, utilização esta não prevista em projeto. Atualmente, este pavilhão encontra-se desativado e passa por um processo de reforma geral. 


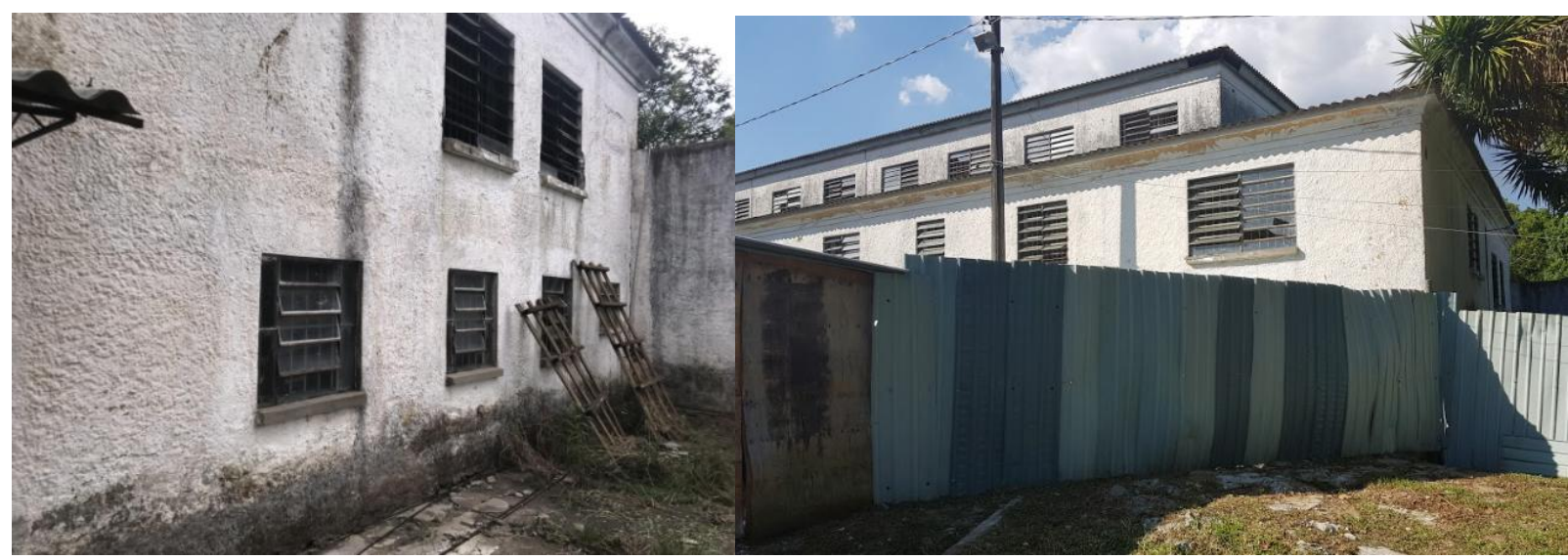

Figura 3: Edificação em estudo.

A investigação foi realizada com base em recomendações da Norma de Inspeção Predial (IBAPE, 2012), restrita, porém aos pontos de interesse deste trabalho. De acordo com a referida norma, a inspeção realizada foi classificada como Nível 1, pela baixa complexidade técnica da edificação e inexistência de plano de manutenção e operação. Devido à idade avançada da edificação, não foram encontrados registros e documentação técnica referentes à sua construção, como projetos, memoriais ou fotografias.

Entrevistas não estruturadas foram conduzidas com membros da equipe do estabelecimento penal, por meio das quais se obteve as informações acerca do histórico do prédio, bem como do uso e manutenção da edificação. Foram inspecionados os elementos que compõem o sistema estrutural do prédio, especificamente na região do subsolo do mesmo, onde as manifestações patológicas mostraram-se dominantes. Adicionalmente, foi conduzida uma análise visual do revestimento interno do local.

Para avaliação do estado de conservação dos elementos estruturais, as anomalias e falhas foram identificadas e classificadas de acordo com sua provável causa e grau de risco. O grau de risco está relacionado aos possíveis danos aos usuários, ao meio ambiente e ao patrimônio, podendo ser considerado como crítico, médio ou mínimo.

Para avaliar o grau de risco das manifestações patológicas presentes no local, foi conduzida, inicialmente,uma análise visual, seguida de ensaios de carbonatação do concreto e identificação da perda de seção do aço. Os procedimentos são detalhados nos itens subsequentes.

Após o estabelecimento do diagnóstico das manifestações patológicas observadas, foram elaborados os prognósticos, indicando as hipóteses de evolução do problema, e, por fim, as intervenções necessárias foram definidas.

\subsection{Análise Visual}

O processo de inspeção acerca das condições da edificação partiu da análise visual in loco, a fim de apontar e registrar, por meio de fotografias, as patologias presentes na estrutura, delimitar a zona afetada e a gravidade e urgência na intervenção, por possível comprometimento estrutural. Através desta análise inicial, deu-se início também o levantamento dos possíveis fatores causadores e/ou potencializadores das anomalias.

A partir do histórico de construção e uso da edificação e com vistas nas condições às quais a estrutura estava exposta, foi possível apontar as principais patologias presentes na estrutura, bem como inferir suas possíveis causas. A figura 4 delimita a zona de estudo da edificação. 


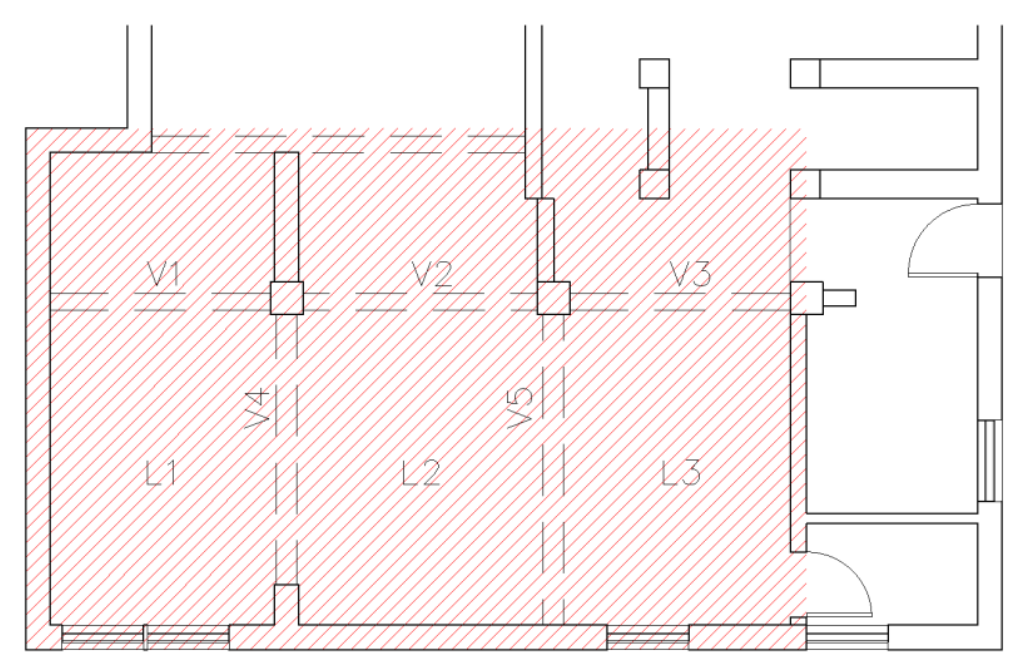

Figura 4: Planta baixa subsolo - área de pesquisa.

\subsection{Carbonatação do Concreto}

Para avaliar a carbonatação do concreto dos elementos estruturais, foi utilizado o método de aspersão de uma solução de fenolftaleína a $1 \%$, diluída em uma mistura de $70 \%$ de álcool etílico e $30 \%$ de água destilada. A fenolftaleína é um dos indicadores de $\mathrm{pH}$ mais comumente utilizados, mantendo-se incolor em contato com substâncias ácidas/neutras e tornando-se cor-de-rosa quando num meio de $\mathrm{pH}$ altamente básico $(\mathrm{pH}>$ 9,5). Dessa forma, quando ocorre carbonatação do concreto, seu $\mathrm{pH}$, alto em condições normais, é reduzido, fazendo a superfície perder seu caráter básico responsável pela passivação da armadura, o que é acusado pela não pigmentação da solução aspergida. Por outro lado, um concreto são é denotado pela coloração rosada que se apresentará após a aspersão.

A solução foi aspergida tanto nos pontos onde a armadura já apresentava-se exposta, quanto em pontos onde foram realizadas janelas de inspeção nos elementos estruturais, conforme figura 5.

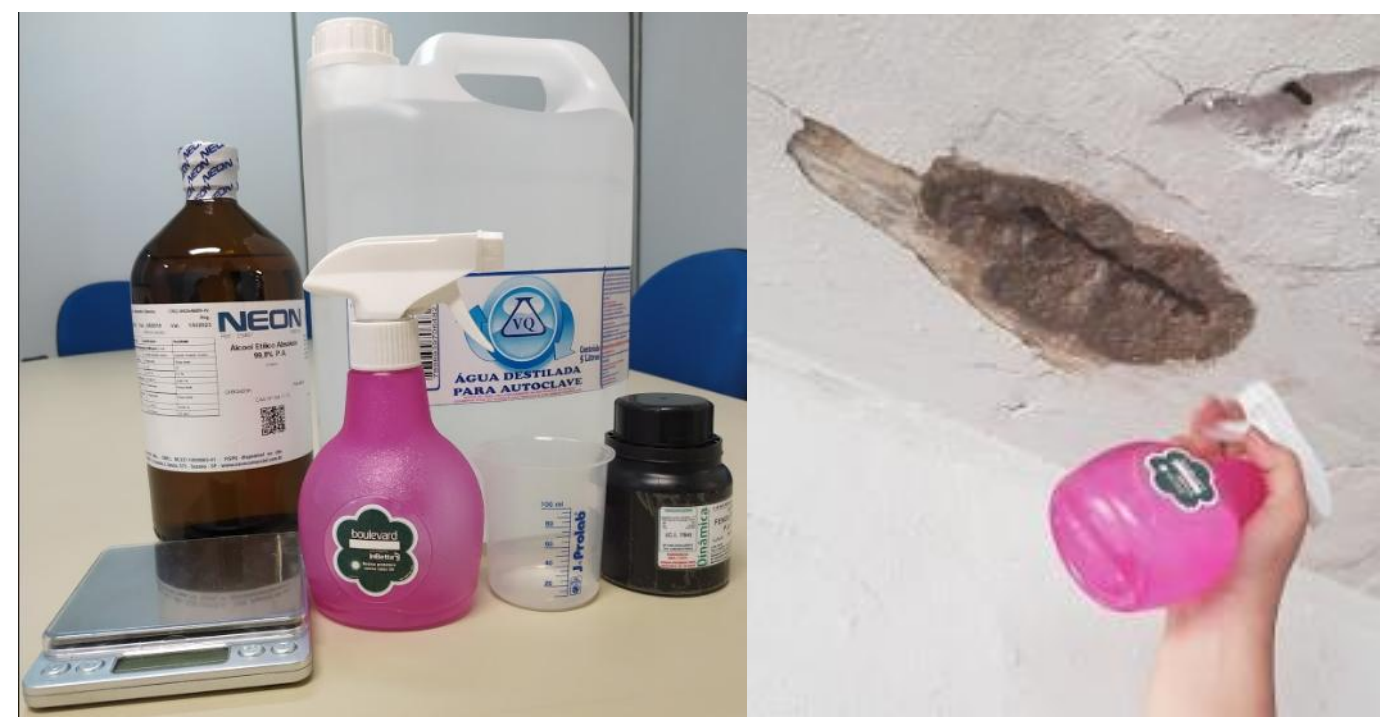

Figura 5: Materiais utilizados no ensaio.

\subsection{Perda de Seção de Armadura}

Com a despassivação das armaduras, o processo de corrosão desencadeado acaba por reduzir a seção transversal das mesmas. A perda de seção do aço nos elementos estruturais avaliados foi determinada por meio de medições in loco. Primeiramente, foi realizada a remoção do concreto que as envolvia, até que fosse possível acessar o diâmetro das armaduras. Com essa fase concluída, procedeu-se à limpeza com escova de aço, visando a remoção de partículas e de produtos da corrosão aderidos às barras. Com a superfície livre de interferências, as medições foram realizadas com 
auxílio de um paquímetro, com grau de precisão de $0,02 \mathrm{~mm}$. O processo utilizado para a aferição da perda de seção está ilustrado pela figura 6 .

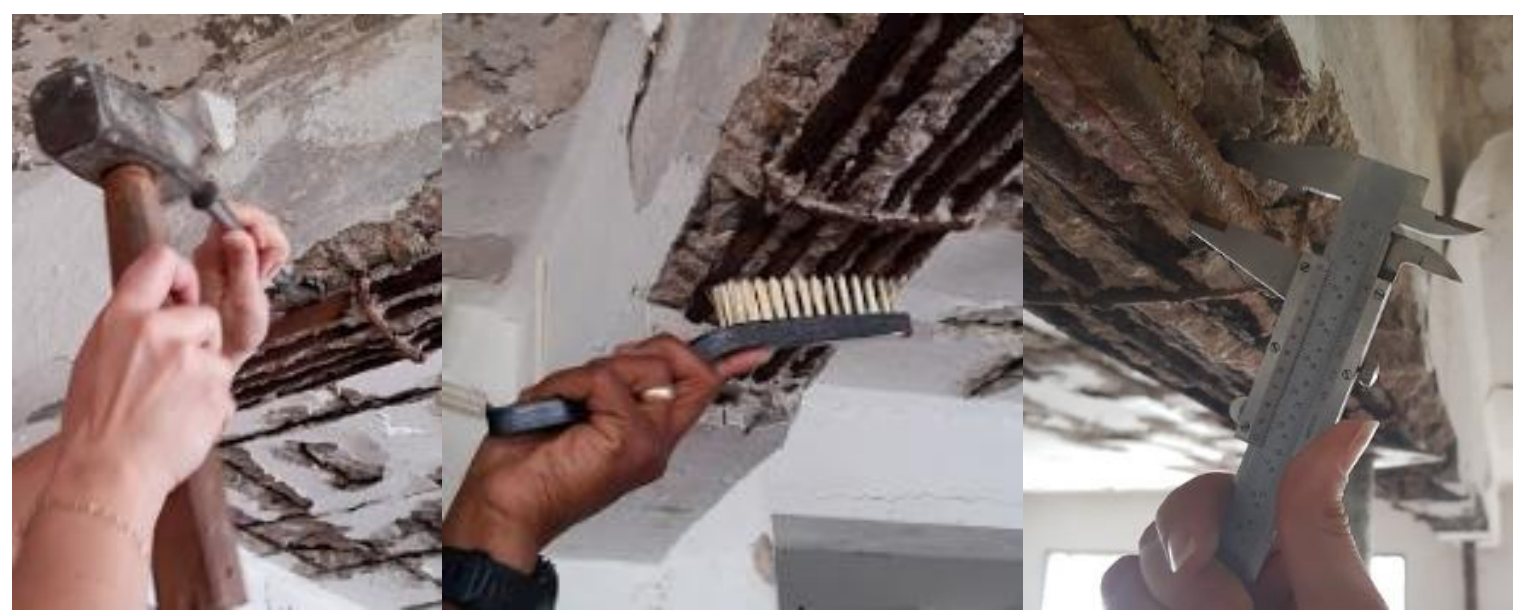

Figura 6: Procedimentos para aferição da perda de seção do aço.

\section{RESULTADOS E DISCUSSÕES}

Com base nos procedimentos de inspeção supracitados, utilizados na vistoria a fim de qualificar e quantificar as manifestações patológicas presentes na estrutura de concreto armado, foram obtidos resultados bastante preocupantes, apresentados nos itens subsequentes.

\subsection{Análise Visual}

A inspeção visual permitiu, já num primeiro contato com a edificação, verificar a gravidade de deterioração à qual os elementos estruturais estavam expostos. A primeira medida tomada foi solicitar escoramento imediato das vigas e lajes do subsolo (Figura 7). Com as medidas tomadas para garantir a estabilidade da estrutura, bem como a segurança dos pesquisadores e dos funcionários da instituição até a intervenção, partiu-se para uma análise mais criteriosa sobre as manifestações patológicos existentes.

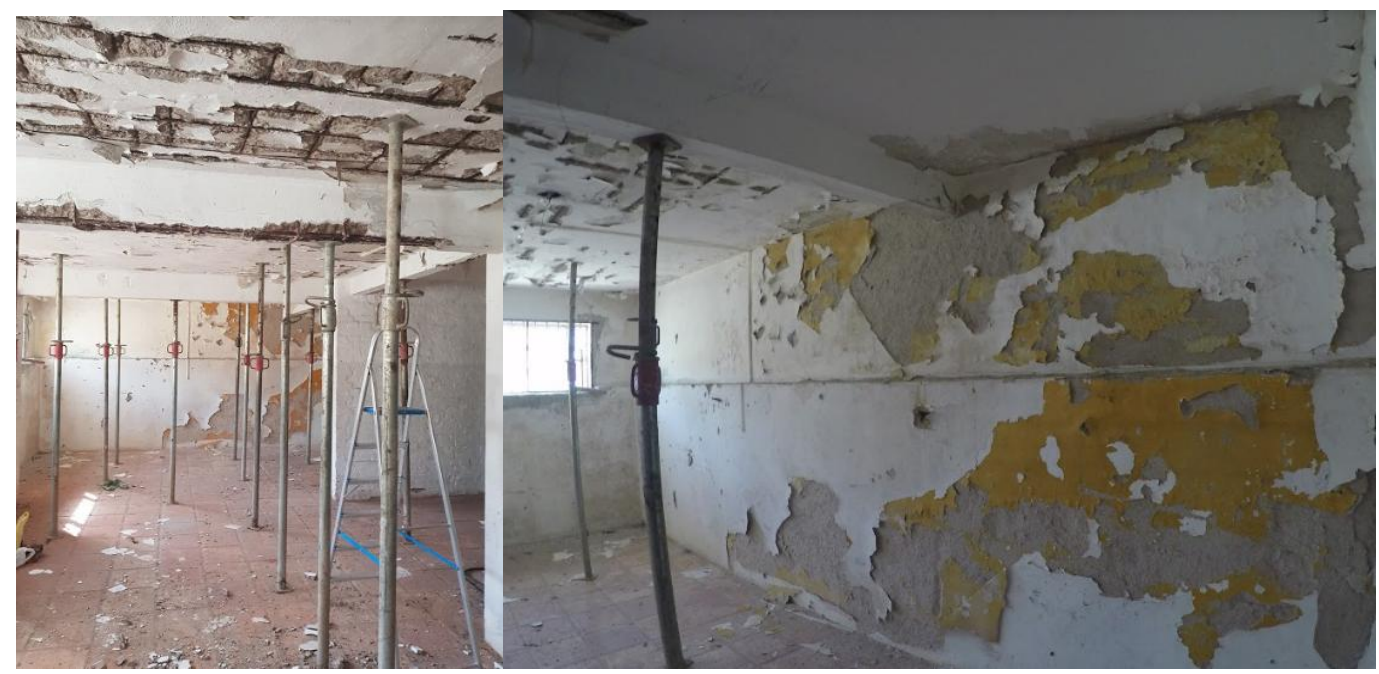

Figura 7: Visão geral do subsolo, já escorado.

Verificou-se que a região de estudo tratava de uma estrutura mista, com vigas e lajes em concreto armado, pilares em alvenaria estrutural e vedação em blocos cerâmicos. A primeira observação foram sinais de presença de umidade, tanto nas paredes, possivelmente advinda do solo, por falta de impermeabilização adequada, quanto proveniente do pavimento superior, utilizado indevidamente como lavanderia. As paredes já apresentavam parte do seu revestimento e pintura descolados, conforme pode ser visualizado na figura 7. Também pode-se observar pela figura 8 indícios da umidade que atingiu as lajes devido ao mau uso da estrutura. Pontos de eflorescência foram identificados em diversos 
regiões das mesmas. Com isso, apontou-se a causa predominante da degradação da estrutura, e uma das mais recorrentes e prejudiciais: presença de umidade.

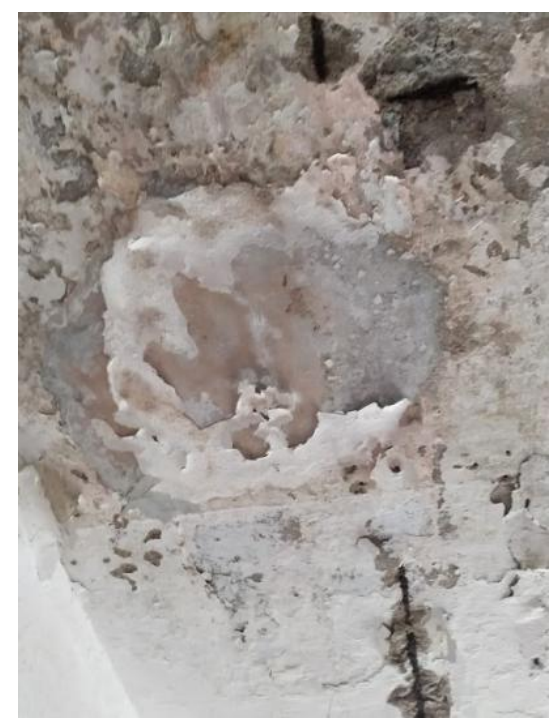

Figuras 8: Detalhe da laje com sinais de eflorescência.

Com relação aos elementos em concreto armado, as vigas e lajes apresentavam diversos pontos sem nenhuma camada de cobrimento, prevista por norma e calculada como o menor valor a ser respeitado ao longo de todo o elemento, para se garantir proteção da armadura, qualidade e durabilidade da estrutura. Nas vigas, isso pode ser explicado pela alta densidade de armadura encontrada nas peças. Foram identificadas como armação positiva das mesmas, cinco barras de diâmetro $16 \mathrm{~mm}$, distribuídas em uma única camada, num trecho de pouco mais de $15 \mathrm{~cm}$ de largura. A distribuição visualizada não respeita os limites mínimos de espaçamento livre entre barras, preconizados pela NBR 6118 (ABNT, 2014). Aliado à grande dimensão dos agregados graúdos utilizados e à porosidade e falta de coesão do concreto, o excesso de armadura foi responsável pela segregação dos materiais, que resultou em um cobrimento composto por material com qualidade inferior ao ideal. Essas características estão ilustradas na figura 9.

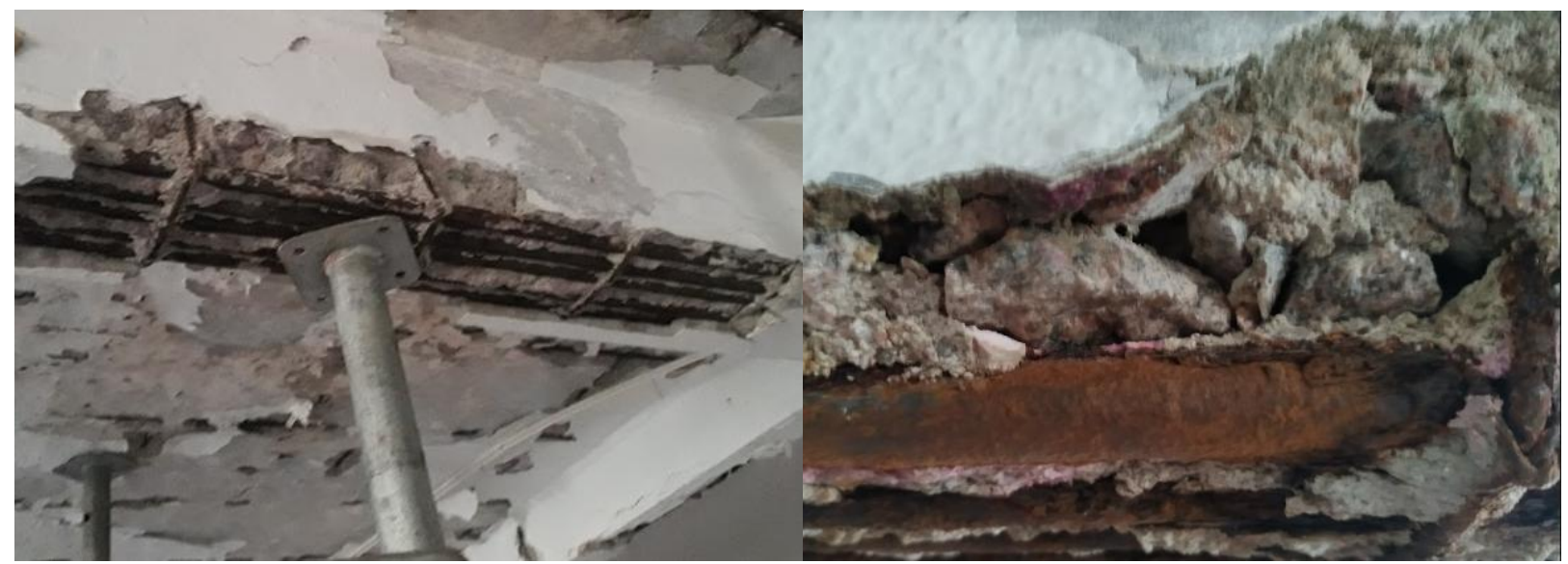

Figuras 9: Distribuição das armaduras e qualidade do concreto das vigas.

Dada a falta de qualidade dessa camada fundamental de concreto, o que foi encontrado no local foram elementos com grande parte das armaduras positivas completamente expostas a agentes agressivos. A consequência disso é o aço com claros sinais de corrosão e com grandes perdas de seção.

Da mesma forma, através da análise visual, foi possível identificar destacamentos na camada de cobrimento inferior das lajes, com exposição das armaduras em grande parte da extensão da mesma. O avanço da corrosão do aço das lajes, em diversos pontos, levou estes elementos estruturais ao que é considerado como mínimo grau de desempenho, atingido quando a armadura perde completamente a aderência ao concreto (figura 10). Nesses pontos, foi possível visualizar o posicionamento original das barras de aço, antes da perda total de aderência, pelas manchas de corrosão remanescentes no concreto. 


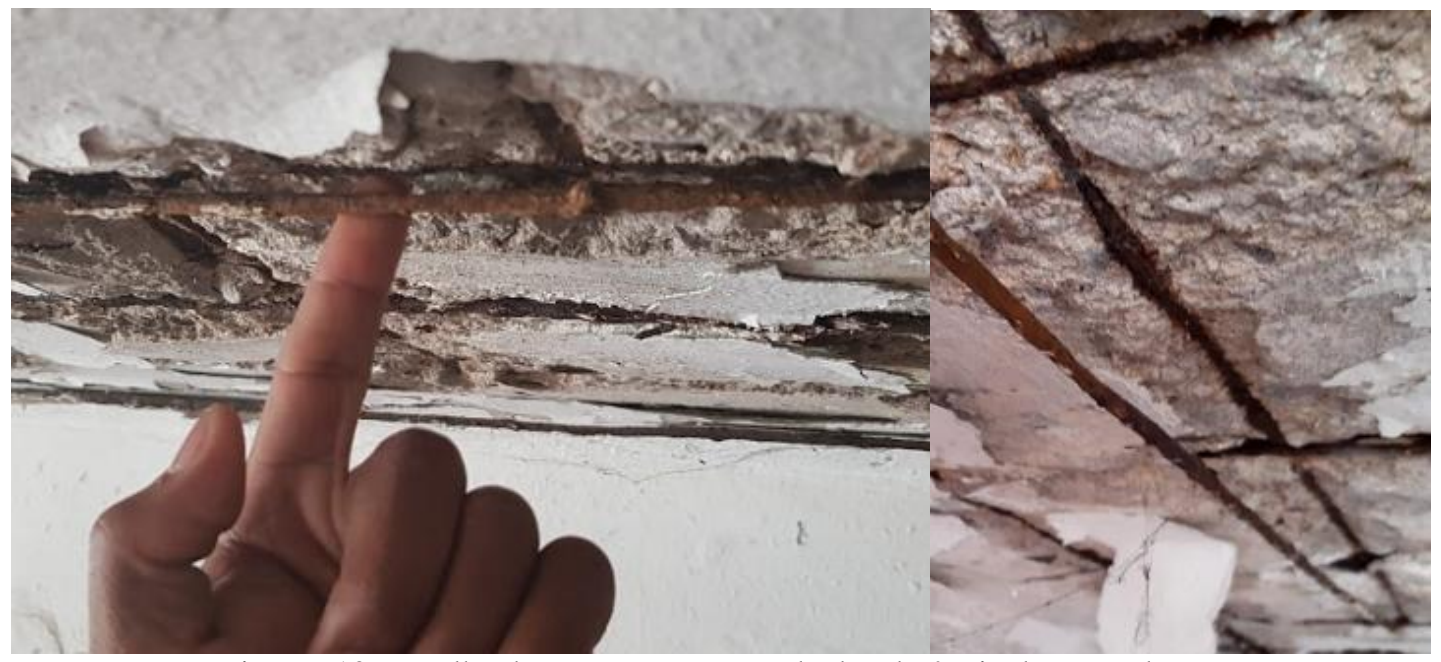

Figuras 10: Detalhe da estrutura com perda de aderência das armaduras.

A análise visual permitiu, também, observar que a armadura sofreu corrosão de forma generalizada, indicando que a mesma foi desencadeada pela carbonatação do concreto. Cabe salientar que na face superior destas lajes não foram observadas manifestações patológicas, devido ao fato de que as mesmas já haviam passado por intervenções durante a reforma geral, em andamento no prédio analisado.

\subsection{Carbonatação do Concreto}

Dadas as condições de degradação da estrutura encontradas durante a análise visual, o diagnóstico inicial foi de que a armadura sofreu despassivação, desencadeada pelo processo de carbonatação, facilitado pela presença de água e pela porosidade do concreto. Com o intuito de corroborar com esse diagnóstico e avaliar o avanço da carbonatação do concreto, foram realizados os testes de aspersão de solução de fenolftaleína.

Conforme esperado, os resultados para as aspersões realizadas nas regiões onde o concreto apresentava-se previamente desplacado, foram de completa carbonatação do mesmo, tanto nas lajes quanto nas vigas. Portanto, a coloração rosa não foi observada em nenhuma aspersão realizada nesses pontos.

Desta forma, janelas de inspeção foram abertas em regiões alternativas, para verificar a propagação da frente de carbonatação nos elementos de concreto. Novamente, em nenhuma das janelas de inspeção abertas a solução aspergida indicou presença de concreto em boas condições. Apenas algumas regiões pontuais da pasta de cimento das vigas apresentaram alteração de coloração, como pode ser visualizado na figura 11.

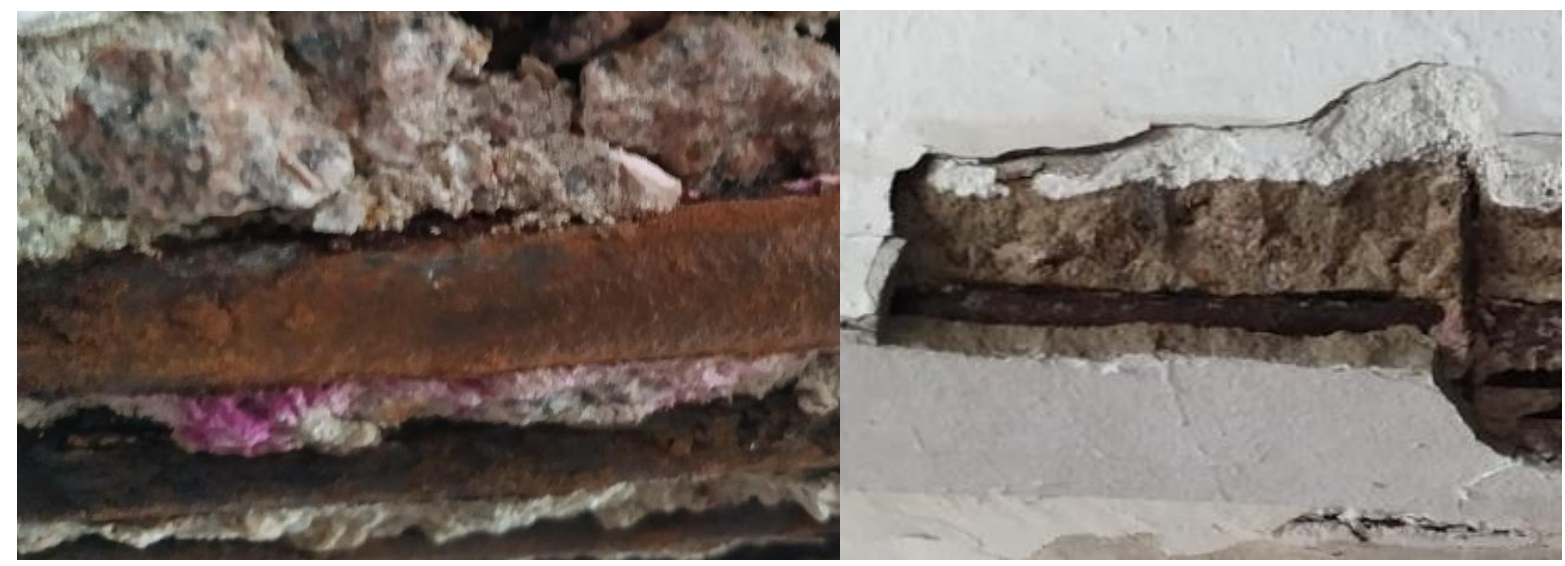

Figuras 11: Regiões aspergidas com fenolftaleína, sem alteração significativa de coloração.

\subsection{Perda de Seção de Armadura}

Para avaliar o nível de dano causado nas armaduras pela corrosão, foram aferidas as perdas de seção das barras. Os resultados obtidos estão descritos na Tabela 1. A perda de seção nas lajes foi substancialmente mais significativa do que nas vigas, atingindo, em média, 27,6\% da seção original. Algumas medidas, nestes elementos, chegaram a apontar perda de seção de até $42 \%$ devido à corrosão. Este fato pode estar relacionado à grande quantidade de umidade a que 
foram submetidas as lajes durante a utilização do pavimento superior como lavanderia, além da má qualidade do concreto e de falhas na execução, que somados à presença de gás carbônico, desencadearam o processo de carbonatação.

Tabela 1: Perda de seção das armaduras devido à corrosão.

\begin{tabular}{c|c|c|c}
\hline Elemento estrutural & $\begin{array}{c}\text { Diâmetro original } \\
(\mathrm{mm})\end{array}$ & $\begin{array}{c}\text { Diâmetro médio aferido } \\
(\mathrm{mm})\end{array}$ & Perda de seção transversal \\
\hline Arm. positiva vigas & 16,0 & 15,48 & $6,4 \%$ \\
\hline Estribos vigas & 5,0 & 4,9 & $4,0 \%$ \\
\hline Arm. positiva lajes & 6,3 & 5,34 & $27,6 \%$ \\
\hline
\end{tabular}

Dadas todas as considerações acima relacionadas, o grau de risco das anomalias da estrutura foi considerado crítico, segundo as classificações descritas pela Norma de Inspeção Predial (IBAPE,2012), apresentando alto risco de "provocar danos contra a saúde e segurança das pessoas [...]; perda excessiva de desempenho e funcionalidade causando possíveis paralisações; aumento excessivo de custo de manutenção e recuperação; comprometimento sensível de vida útil”"

O prognóstico para as patologias observadas é de que as mesmas avancem para um possível rompimento e colapso, parcial ou total, caso nenhuma intervenção ocorra.

\section{SUGESTÕES DE INTERVENÇÃO}

Diante dos resultados obtidos por meio da inspeção da edificação, dado o diagnóstico negativo que aponta grau elevado de deterioração dos materiais e elementos estruturais, partiu-se para a definição das intervenções necessárias para a recuperação da vida útil da estrutura.

Uma das soluções de recuperação e reforço estrutural consiste na substituição e/ou tratamento do aço corroído e incremento de armadura. Primeiramente é feita a remoção do concreto remanescente do entorno da armadura, através da escarificação do mesmo, até que seja encontrado concreto são. Em seguida, procede-se com a limpeza da armadura a fim de retirar todas as partículas e produtos da corrosão do material. Este processo pode ser realizado através do lixamento da superfície, ou com auxílio de jatos de areia. Como praticamente a totalidade das armaduras positivas, tanto das lajes quanto das vigas, apresenta-se em estado crítico de corrosão, o processo manual de limpeza demandaria um tempo significativo de trabalho. A alternativa de limpeza com jato de areia, por sua vez, poderia representar risco à integridade do concreto, que se apresentou bastante abrasivo. Desse modo, a técnica para limpeza das armaduras deve ser ponderada de forma a optar-se pela alternativa que melhor se adeque às características locais. Tendo sido executada a limpeza de todas as armaduras, estas devem ser cobertas com uma pintura de proteção a base de zinco, que serve como ânodo de sacrifício para possíveis ataques futuros. Por fim, é feito o incremento de armadura, sobretudo nas regiões onde a perda de seção do aço foi predominante. Nas lajes, esse incremento pode ser realizado com o uso de telas de aço eletrosoldadas, ancoradas aos elementos estruturais existentes e devidamente recuperados. As armaduras de reforço são fixadas por meio de estribos que devem ser levados até as faces superiores das peças. Por fim é realizada a integralização da seção com argamassa aditivada com sílica ativa, graute ou concreto projetado, garantindo o cobrimento das armaduras, previsto por norma.

No entanto, dada a possibilidade de recuperação e reforço da estrutura supracitada, sua dificuldade e custo elevado que envolve a execução das mesmas, recuperar a estrutura, sobretudo as lajes, pode não representar a melhor solução, com relação a viabilidade econômica e técnica. Isso se deve sobretudo à precariedade do concreto existente que, por se tratar de uma estrutura antiga e com pouco controle de execução, não apresentou qualidade satisfatória. No processo de análise da zona carbonatada do concreto, por exemplo, mesmo com aberturas de janelas de inspeção profundas não foi encontrado concreto são, o que seria condição necessária para a recuperação dos elementos. Tais resultados, somados ao grau crítico de corrosão da armadura e perda considerável das seções transversais dos elementos, podem dificultar ou inviabilizar métodos de reforço e recuperação, ou tornar o processo muito oneroso. Diante disso, a opção por substituir parcialmente a laje existente também deve ser ponderada, podendo se mostrar mais viável ou até mesmo necessária. Tal ponderação deve ser realizada com base na avaliação do custo e da viabilidade de execução de ambas as opções, considerando-se o sistema estrutural como um todo e os demais elementos envolvidos, bem como de mão de obra especializada para os serviços a serem executados. 


\section{CONCLUSÕES}

A pesquisa em questão trata dos resultados obtidos a partir de um levantamento de dados referente a um estudo de caso de manifestações patológicas de estruturas de concreto armado em um estabelecimento prisional.

Por meio das análises visuais, ensaios de carbonatação, aferição das porcentagens de perda de seção transversal das armaduras das peças e pesquisa sobre o histórico da edificação, foi possível fazer o diagnóstico das patologias presentes na estrutura. Pôde-se constatar que a água foi o elemento causador da maior parte das manifestações patológicas. Ainda, foi possível apontar falhas de execução, de projeto e materiais que não garantem as propriedades exigidas por norma.

Dessa forma, é possível inferir que o uso da edificação para fins não previstos foi responsável por acelerar a degradação da estrutura, reduzindo sua vida útil. Tais resultados permitiram concluir que são muitos os problemas estruturais ocorridos na área analisada, e estes poderiam ser evitados caso houvesse sido realizadas manutenções preventivas, bem como, utilizações adequadas dos ambientes internos. Ainda, percebe-se como a atenção no processo de projeto, execução e cura podem ser decisivos na vida útil e comportamento da edificação.

Em suma, mesmo com limitações de ensaios, tornou-se possível concluir que a edificação não está em condições ideais de abrigar os internados. Não foi possível encontrar concreto são em nenhuma superfície, tampouco em janelas de inspeção profundas, e as armadura, praticamente expostas em sua totalidade, não cumprem mais sua função estrutural devido ao nível de corrosão. Assim, a estrutura, classificada como grau crítico, representa uma situação de difícil recuperação, devido a severidade e estágio avançado das manifestações. Os procedimentos sugeridos para recuperação envolvem a limpeza da superfície do concreto e do aço, a proteção superficial da armadura e a posterior recomposição das seções danificadas. Caso tais procedimentos se mostrem de difícil execução ou demasiadamente onerosos, a substituição da laje pode ser ponderada.

\section{AGRADECIMENTOS}

Agradecemos ao Departamento de Tratamento Penal da Susepe - DTP, à Engenharia Prisional da Susepe e à direção do estabelecimento penal por confiar no nosso trabalho, pelo apoio e por permitir com que nossos objetivos fossem alcançados com sucesso.

\section{REFERÊNCIAS}

ASSOCIAÇÃO BRASILEIRA DE NORMAS TÉCNICAS. NBR 15575-1: Edificações Habitacionais - Desempenho. Requisitos Gerais. Rio de Janeiro, 2013.

ASSOCIAÇÃO BRASILEIRA DE NORMAS TÉCNICAS. NBR 6118: Projeto de Estruturas de Concreto Procedimento. Rio de Janeiro, 2014.

FIGUEIREDO, Enio José Pazini; MEIRA. G. Corrosão das armaduras das estruturas de concreto. In: Geraldo Cechela Isaia. (Org.). Concreto: ciência e tecnologia. 1ed.São Paulo: Arte Interativa, 2011, v. 1, p. 903-931.

HELENE, P.R.L. Corrosão das armaduras em concreto armado. 1. ed. São Paulo, PINI, 1986.

INSTITUTO BRASILEIRO DE AVALIAÇÕES E PERÍCIAS DE ENGENHARIA (IBAPE) - Norma de Inspeção Predial Nacional, 2012.

MAIA, Clarissa Nunes et al. História das Prisões no Brasil. 2. ed. Rio de Janeiro: Rocco Digital, 2013. 132 p.

MEIRA, G. R.. Corrosão de armaduras em estruturas de concreto : fundamentos, diagnóstico e prevenção. João Pessoa : IFPB, 2017.

SOUZA, A.; MONTEIRO, E., BATISTA, T. Manifestações patológicas encontradas em reservatórios de água de edifício residencial. In: Conferência Nacional de Patologia e Recuperação de Estruturas, 2017. Recife. Anais... 2017.

TUTIKIAN, B. F.; PACHECO, M. O que é Inspeção, Diagnóstico e Prognóstico na Construção Civil? Mérida, México: Alconpat Internacional, 2011 (Título de los Procedimientos Recomendables de Alconpat Internacional). 